\title{
Moral responsibility and action in the use of artificial intelligence in construction
}

Philip McAleenan PhD

Consultant, Expert Ease International, Downpatrick, UK (philip@expertease.ie)

Rapid increases in processing power and speed of computing coupled with development of self-learning algorithms capable of autonomous decision making are central to current technological developments. This has fed dystopian visions of either out-of-control robots malevolently destroying humanity or benevolent robots enslaving humanity as a result of acting for its own good. A more nuanced assessment demonstrates that inherent in any benevolent intent is the unintended potential for harm, which must be addressed in parallel with if not in advance of developments in the field. This paper examines the hazards and challenges presented by artificial intelligence in respect of construction. In conjunction with developments and guidelines on machine ethics, it outlines the issues and posits how they may be addressed by governments, designers, contractors and worker organisations to access the growth potential of the sector as a socially responsible industry.

\section{Introduction}

The fourth industrial revolution is to be characterised by the processing power and speed of computing combined with the development of self-learning algorithms with the potential for autonomous decision making that is independent of the programmer or controller of the device/system. This has fed dystopian visions of either out-of-control robots malevolently destroying humanity or benevolent robots 'enslaving' humanity as a result of acting literally for the good of humanity, a vision that Rolf et al. (2018) suggest stems from an error in the overestimation of the capabilities of artificial intelligence (AI) and underestimation of human intelligence.

Setting aside such visions, a more nuanced assessment of the capacity for AI, as it is known, to be used in ways that undermine privacy (Choi et al., 2017; Hovden et al., 2010; Sekiguchi and Hori, 2020) or to make decisions and initiate actions outside the control of those affected by the decisions clearly demonstrates that inherent in any benevolent intent is the potential for harm (Winfield et al., 2019), which must be addressed in parallel with if not in advance of developments in the field (Sekiguchi and Hori, 2020).

Both private and public sector institutions are addressing the moral and ethical challenges. The Future of Life Institute (FLI, 2019) has developed the Asilomar principles for AI and the European Commission (AI HLEG, 2019) the guidelines for ethical use of AI. Neither is a legally binding document. Both reacknowledge the primacy of human safety and well-being and outline principles that developers and users of AI should consider in both development and application. The Institute of Electrical and Electronics Engineers (IEEE), a technical and professional organisation for advancing technology, has been developing standards for a number of years specific to the ethics of AI (Winfield, 2019) and in 2016 launched a global initiative on the ethics of autonomous and intelligent systems (A/IS), publishing standards (2017) based on sets of ethical principles (Table 1). At the core of the IEEE initiative is human well-being.

Also in 2016, the first explicit standard on robotics was published by the British Standards Institution (BSI) as guidance for designers on how they can conduct an ethical risk assessment of their AI system and to mitigate such risks as emerge from the assessment (BSI, 2016).

This paper examines the hazards and challenges presented by AI in respect of the construction industry and, in conjunction with existing legal standards, outlines the occupational safety and health (OSH) issues and how they may be addressed by governments, designers, contractors and worker organisations.

\section{Background}

Data are at the core of advances in AI. Modern society has generated a phenomenal wealth of data and the means of storing it in a quick and easily retrievable manner. Furthermore, the technology of retrieval encompasses the technology of interrogation, with information being classified, sorted, cross-referenced and otherwise manipulated to provide detailed information on specifics or broad patterned information of a general nature that permits the world to be seen in new and different ways. On the internet, the ability of data manipulators and information providers to influence what the users view or direct their browsing is indicative of the pervasive nature of AI systems and their potential to distort how humans conceive themselves within society or as a society (Hogan-Doran, 2017: p. 348; Pereira, 2018: p. 14).

What AI contributes to these advances is its ability to gather, analyse, create and control the types of world views that it generates in a unique manner. Compared with earlier technologies that required the human operator to decide how to interrogate the data, AI 'self-learns'. In AI, the underpinning algorithms recognise patterns, adjust their actions, make assumptions to 
Table 1. Round-up of robotics and Al ethics (Winfield, 2017)

$\begin{array}{llc}\text { Principles } & & \text { Author } \\ \text { Three laws of robotics } & \text { Isaac Asimov } & \text { Year } \\ \text { Three laws of responsible robotics } & \text { R. Murphy and D. Wood } & 1950 \\ \text { Principles of robotics } & \text { Engineering and Physical Sciences Research Council } & 2009 \\ \text { Asilomar principles for beneficial Al } & \text { FLI } & 2010 \\ \text { Principles for algorithmic transparency and accountability } & \text { The Association for Computing Machinery US Public Policy Council } & \text { January } 2017 \\ \text { Ethical guidelines } & \text { Japanese Society for Artificial Intelligence } & \text { February } 2017 \\ \text { Draft principles } & \text { The Future Society's Science Law and Society Initiative } & \text { October } 2017 \\ \text { Draft principles } & \text { Montréal Declaration for Responsible Al } & \text { November } 2017 \\ \text { General principles of ethical AVIS } & \text { IEEE } & \text { December } 2017 \\ \text { Top ten principles for ethical AI } & \text { UNI Global Union } & \text { December } 2017\end{array}$

interrogate the data and produce information, recommendations and so on based on those assumptions. In this manner, search engines produce unasked-for recommendations to users based on assumptions determined by the patterns that the AI sees in previous searches and computers produce music, poetry and art based on subtle patterns recognised by AI that allow it to go beyond mimicry and produce new works as if the original artist or author had or would have produced them (du Sautoy, 2019).

In medicine AI, IBM's Watson computer was first mooted in 2011 as having the potential to assist in the diagnosis of illness and the recommendation of treatment. $\mathrm{AI}$ assists in the management of traffic flow and the control of self-driving, sometimes referred to as autonomous, vehicles and trains such as those used by Rio Tinto in Australia's extraction industry.

In crime work, AI searches for patterns in order to predict behaviours that lead to criminality or where crimes may occur in a community so that police resources may be effectively directed. The facial recognition systems developed for London's Olympics construction was considered by the police for use in policing the games themselves (Leyden, 2008). Buying habits are analysed and product recommendations are made and, more sinisterly, political positions are analysed and voter decision making is influenced by the dissemination of targeted and, particularly, false information. In construction design, transformative software can explore a myriad potential solutions and proffer design alternatives (Johnston, 2019), including offsite construction methods, using autonomous assembly-line processes, which now compete with traditional building techniques.

Furthermore, with the availability of wearable technology, whether for collecting data or for directing worker performance (Choi et al., 2017; Kortuem et al., 2007; Zeng et al., 2019), onsite worker performance and conformance monitoring by using facial recognition software, dressed up as safety measures, is now practical. The Olympic Development Authority used both palm and facial recognition technologies to monitor and screen up to 100000 workers over the course of the construction of the London Olympics project (Leyden, 2008), and the Balfour Beatty, Morgan Sindall, Vinci Construction consortium introduced wrist-worn devices to monitor and reduce fatigue at sites on the
Crossrail project in London (Wilson, 2018). The Hong Kong underground system has been using AI to facilitate effective maintenance, reduced planning time, productivity efficiencies and cost reductions (Hodson, 2014).

Overall, AI has the capacity for good, for deviousness and for malign purposes. Although what is important to recognise is that this is not some type of autonomous dystopian machine with intent of its own, but rather tools designed, programmed and used by humans for human purposes. In addition, awareness of this goes to the core of considering the moral and ethical implications of gathering data in work environments and using AI to interrogate those data and make recommendations for human action.

\section{Some issues}

\subsection{Weak and strong Al}

AI systems can either be categorised as weak AI, involving only processing of specific tasks with a high degree of human supervision and decision making (although it may be programmed to handle very simple decisions), or strong $\mathrm{AI}$, which has the capacity for processing multiple tasks with human-like intelligence, capable of complex decision making, classified as artificial general intelligence (Wang and Siau, 2018).

The stuff of nightmares or an enlightened vision of the future, depending on one's perspective, is the strong AI that reaches the level of full autonomous AI, with the capacity for advanced selflearning, reflection, deliberation and autonomous opaque decision making without the mediation of a human agent. At this stage of development, the AI artefact may have achieved the status of full ethical agency with consciousness, intentionality and free will and may be considered a conscious entity rather than merely an artefact and lay claim to equal status with humans (Wang and Siau, 2018).

On this creation, however, this paper will address no further, as it is of little immediate relevance to the technologies being employed today, although it is not beyond the realms of enlightened governments' considerations. For example, Germany has prohibited the development of machines that make distinctions based on personal features or offsetting victims against one another (e.g. as in the trolley problem - an ethical 
thought experiment wherein one is in charge of making a choice between letting five workers on a track face death from a runaway trolley or saving them by pushing a sixth person in front of the trolley, thereby killing this person - or driverless vehicles) (Winfield, 2019).

What is relevant are AI systems that are designed to facilitate human decision making, and when focusing specifically on the construction industry, a wide range of projects that are in operation or development are centred on matters of $\mathrm{OSH}$ monitoring (Choi et al., 2017; Kortuem et al., 2007); site security, risk identification and prevention (Li et al., 2015); accident analysis (Andolfo and Sadeghpour, 2015; Hovden et al., 2010); and quality and performance enhancement (Waber et al., 2007; Yu et al., 2017). Within these types of systems, data are collected and/or collated (often locally and for local application of decisions) with mostly specific beneficial intent - for example, to improve health and safety on-site.

In some examples, the system monitors the movements of workers and plant and their locations, analyses the potential for accidents - for example, collisions - and informs the workers or issues instructions of what to do to prevent the accident (Andolfo and Sadeghpour, 2015). Other systems gather and analyse data from accident reports, search for patterns and produce information and, increasingly, recommendations on how to alter (or use) those patterns to achieve specific objectives and outcomes (Baker et al., 2019). Still further systems monitor performance and behaviours and produce recommendations and instructions for behavioural modification to maximise productivity and efficiency.

\subsection{Ethics deficit}

McAleenan et al. (2019) identified the ethics deficit in OSHmonitoring technologies as existing between the intent to produce beneficial technologies for construction safety and the practice of developing that technology but without giving sufficient consideration to the intended beneficiary, the worker, a human agent with natural consciousness, intentionality and free will. The literature on AI generally has addressed and is addressing the ethics issue and is substantial. Standards bodies, such as the IEEE and the BSI; governments (e.g. EU); and concerned scientists, philosophers and other professional individuals (e.g. those that form the FLI) are among many who are researching and producing guidelines for system designers and developers (Table 1), and all recognise that technological developments are occurring faster than philosophical and ethical considerations are able to keep up.

The issues do not simply boil down to Asimov's first law of robotics; 'a robot [AI system] may not injure a human being, or through inaction, cause a human being to come to harm' (Asimov (1942), cited by Salge (2017)). Although, no doubt, this ought to be the core tenet of any AI system and the research facilities that design and develop such systems, the problem, however, at its simplest, is twofold: how to interpret 'ought not to harm' and how to program the system to exercise that 'ought'. (Note that this 'rule' equates, in part, to the fundamental rule of moral behaviour to do no harm, although it does not encompass the corollary that the system 'ought to do good'.) Asimov's laws work well in an uncritical reading of his novels, but real-world attempts to incorporate them into AI design require continual qualification and additions, hence the nine subsequent sets of guidelines and principles (Table 1).

Sekiguchi and Hori (2020: p. 51) more recently argue that AI studies have not incorporated the results of academic societies into their research into AI ethics because the subject is too broad and the information is too large such that engineers have little time to understand and construct the relationship between their own work and ethics. In some respects, engineers view ethics as too abstract and a far cry from the practical hands-on activity of writing a program or building a machine, although their argument is in part negated by the efforts of the IEEE (a standards body of electrical and electronics engineers) to identify the ethics issues and develop appropriate standards (Winfield et al., 2019), standards that have guided their research and development of an AI ethics tool for engineering design (Sekiguchi and Hori, 2020).

\subsection{Codified ethics and moral responsibility}

Ashe (2019: p. 1), on the other hand, approaches the matter from a critical ethical stance, arguing that attempts to establish ethics guidelines for AI systems are doomed to failure as such guidelines are missing the 'ethically implicating questions: What is ethics? Who gets to be ethics makers and ethics proclaimers? And what principles and relations are, well, good?' Her work, grounded in critical theory, argues that the codification of ethics in guidelines and algorithms institutionalises or codifies good and thereby limits or perverts it.

The critique by Ashe (2019) defines the prevailing generalising paradigm as techno-ethical, wherein 'technique' (e.g. guidelines and algorithms) limits people in as much as it negates their capacity for face-to-face encounter with others. This compromises responses to others, particularly the responsibility to respond to others as victims, understood as the fully embodied relationship felt as a personal call rather than as an incidence of institutionalised ethic - that is, the individual is restricted, even prevented from fully relating to another outside of the rules that quantify their relationship (the Good Samaritan, as understood by Ivan Illich, quoted by Cayley (2015)). In a more general sense, these are issues that emerge from considerations of deontological ethics and whether codified ethics can be universally sufficient.

Ashe's critical ethical approach articulates in a deeper philosophical sense the concerns that others have raised regarding ethics. Wang and Siau (2018: p. 438) recognise that ethics is a 'complex, complicated and convoluted concept' that in the application of AI poses the question on moral responsibility for failures when humans and AI systems work in conjunction. Who or what, for example, bears the responsibility for a workplace fatality when instructions to act were issued by a human agent informed by an AI system? 


\subsection{Moral ambiguity}

Pereira (2018) articulates the perennial moral philosophical problem of moral rule making in the absence of sufficient knowledge of or agreement on what ought to be done in any and all circumstances. He argues that humans do not know their own morals well enough to be able to program these. Even with what moral knowledge that humans do have or ethics philosophy they adhere to, humans nonetheless continue to exploit humans, ergo human-designed (AI) systems will inevitably mimic human behaviours, including exploiting or being manipulated ('corrupted' as per Illich, cited by Ashe (2019)) to exploit other humans. Choi et al. (2017) address the concerns of workers in respect of requirements to wear 'smart vests' and the potential for their 'idle time' being recorded and thus the potentiality of increasing their productivity by elimination of such time.

This aspect of moral behaviour, that humans exploit humans and by extension cause harm to others, is a defining feature of moral agency. The moral agent not only knows what they ought to do and what they ought not to do but also has the capacity to choose to act immorally - that is, to do what they ought not to do. This capacity is a major obstacle to the development of autonomous AI systems. Notwithstanding the complexity of such programming, an AI system with a decision making capacity, even at the simplest levels, must be 'educated' in what it ought and ought not to decide (Rolf et al., 2018; Wang and Siau, 2018) but constrained from intentionally deciding to do what it ought not to do - that is, constrained from intentionally acting immorally.

This notion is leading back to the concept of the fully autonomous conscious AI system, which is beyond the scope of this study, although it is what Rolf et al. (2018) had in mind when they discussed society's overestimation of the capabilities of AI and underestimation of human intelligence. Nevertheless, in recognising the work done to build an 'ethical reasoning' by way of a deontic approach, they acknowledge that it remains insufficient for the breadth and complexity of human interactions. They may be signalling that AI should not or could not achieve the capacity to interact fully and autonomously with human beings and that the separation of AI systems and humans is maintained through human control of the system. Ashe (2019) would disagree that the latter is not possible.

\subsection{Codifying law}

AI, Rolf et al. (2018) state, does not have to be ethical in the sense of having cognition or deliberations, but it must be constrained to comply with the law. However, Hogan-Doran (2017), coming at the problem from a legal background, recognises the benefits in terms of accurate, consistent and costeffective decision making but raises questions about authorisation, reviewability and the difficulties about applying legislations, solving complexities and ambiguities and the potential for coding errors. In this, she reiterates from her own specialist perspective issues that others have raised in respect of complexity and ambiguity in human affairs that have not been or are not resolvable in the human mind and that are greatly problematic if encoded within AI algorithms.

Law is made by legislators, interpreted by the judiciary and enforced by regulators. Encoding what the legislators have written may be of assistance to the regulators who use AI systems to inform them of what was written to allow them to make decisions or even to accept decisions made by the system itself. However, the problem with law is that the meaning of the text is often far from clear and needs interpreting. By way of example, the phrase 'so far as is reasonable practicable' is a qualifier to prevent absolutes in UK health and safety law but was not defined in statute and therefore required the deliberations of the judiciary to determine its meaning (Edwards v. National Coal Board [1949]). However, their determination that there should be no gross disproportion between the quantum of risk and the measures (whether in money, time or trouble) necessary to avert that risk is no less ambiguous when it comes to developing a code by which AI can apply the qualifier.

It is either beyond the capacity of AI systems to interpret the intent of the legislature or, if the algorithms so facilitate, currently socially unacceptable for the system to interpret the meaning of laws and apply its decisions when humans are directly impacted by those decisions possibly without recourse to appeal.

Hogan-Doran (2017) raises other critical issues with this use of AI systems:

accountability

- who or what laws authorise the decision maker

- whether AI or human

- automatic decisions against discretionary decisions

- technology for assisting the decision maker

- framing the decision makers' considerations and determinations of what is/is not selected (i.e. it directs their thinking)

- the removal of human decision making from the process

- data mining and profiling.

Consider, for example, AI monitoring systems (Choi et al., 2017; Kortuem et al., 2007) designed to monitor worker and plant movements on a construction site, predict potential collisions and inform workers and plant operators how to act to avoid the collisions. Is the design of the AI system paramount, or can the workers accept the information provided and make their own, different decision? In an investigation of a collision or a negative outcome of a worker's decision to act to the contrary, will the investigator's mind remain open knowing the company's investment in the AI system? These are issues that are amenable to academic discourse and potentially resolution, but within the elaborations of these matters, Hogan-Doran (2017) abstracted and elevated a primary obstacle to the resolution of them - that is, the 'black-box' problem.

\subsection{The black-box problem}

Artificial neural networks (ANNs) are machine learning systems that learn and solve problems without being programmed and 
with the minimum of human guidance. This capacity renders the processes of the system opaque, not amenable to observation, analysis or understanding (although developing mathematical models may overcome this in the future), hence 'black box'. In fully automated systems, the inputs and most of the outputs are also in the box.

The capacity for ANNs to confound programmers was demonstrated in 2017 when Google's DeepMind project developed the AlphaGo program to play the strategic board game 'Go' against world masters. The game has $2 \times 10^{170}$ legitimate moves, and by playing against itself hundreds of millions of times, the program learned and was able to beat the masters most times. A super version, AlphaGo Zero, in 2017 defeated the earlier version 100 times to 0 (du Sautoy, 2019). This latter version was created without using data from human games, and it may presage the development of algorithms with skills that humans do not have (Meyer, 2017).

Decisions that impact individual human liberty and well-being must be explainable and transparent. Each person has the right to be informed of how and why a decision was made and, where a different decision could have been made, what were the determinants that made the choice. AI systems designed as a neural network are not amenable to transparency and explanation, even to the creators, much less the person affected by the process.

The problems of transparency and explanation are not confined to ANNs but arise too as a result of, for example, secret algorithms or inputs, secret implementations and imprecisely described processes (Hogan-Doran, 2017). In the case of algorithms, these are often protected by trade secrecy laws. Without transparency and explanation, accountability cannot be established and the thesis of the faceless other by Ashe (2019) is realised, but in this case as an unknowable AI system.

\section{Towards solutions}

The issues described here are by no means exhaustive, and questions of programmer bias (Wang and Siau, 2018), cultural noncorrespondence (Winfield et al., 2019), prediction and probability (Morley and Floridi, 2019; Pereira, 2018) and social and societal relationships (Morley and Floridi, 2019) are no less important by not being elaborated on here. The danger is in presenting a negative and bleak picture of $\mathrm{AI}$ when in fact the raising of the issues is necessary to exploring potential solutions. The postapocalyptic works of science fiction author Ray Bradbury serve not as a warning that they would happen but as a description of what society needs to avoid (Karaca Kucuk, 2013). As with the issues, the following is limited to openings addressing core problems associated with moral accountability and to methodologies for implementing ethical practice in design.

Whatever the philosophical difficulties and technical complications of programming any type of ethic into AI systems, weak or strong, the starting point is always with the designer/ developer of the system and to some extent the client and investors in the project. Assuming beneficent intent is not enough to view the project as simply a technical challenge to meet the client specifications - for example, how to build an accidentprevention system through the collection and analysis of data (Baker et al., 2019).

Such systems may collect, collate and analyse data from accident and incident reports, employee health and fitness records, social and recreational activities, on-site behaviours by way of monitoring and facial recognition technologies, wearable and implantable health and stress technologies and so on, all of which can be analysed to pinpoint behaviours, personal susceptibilities to ill health, site practices and layouts and so on with a high potential for harm and produce information designed to prevent or mitigate that harm - for example, preventing on-site collisions by location monitoring of plant and personnel (Andolfo and Sadeghpour, 2015).

The Baker et al. (2019) model is designed to augment human decision making, and it is recognised that further work is required to determine the extent to which this method does improve that decision making. However, as discussed, the good intentions of the client and the best efforts of the designer give no assurance as to how the AI system can or will be used by misinformed, incompetent or malicious end users, nor can they be a guarantee of acceptance by a workforce suspicious of employers' intent and conscious of the potential to limit autonomy.

It may be argued that how a product is used and the harm that it may cause is not the responsibility of the designer, developer or manufacturer but of the end-point user whose use of the system causes the harm (excepting situations where the harm is traceable to a design or manufacturing fault or error). A common example in both moral philosophical discourse and legal action concerns the responsibility of a manufacturer of a gun (or the tenth-century Chinese inventor) for the action on a third party who uses the gun to murder another.

In criminal cases, 'mens rea' (guilty mind) and 'actus reus' (guilty act) are critical but civil actions that centre on duty of care: whether a duty was owed, whether the defendant did or omitted something that led to the action and whether the plaintiff suffered harm as a result. In legal terms, it is difficult to prove a case of liability when there is a remoteness between the moral agent and the individual acted on and is impossible if any of the aforementioned legal prerequisites are not established. However, 'responsibility' is a concept different from 'liability' and in ethical discourse has a different meaning. It certainly does not necessitate guilt, and designers may reflect on the nature of any responsibility that they may bear towards those impacted by their system in the hands of a more remote unknown moral agent.

In UK Construction (Design and Management) Regulations 2015 terms, the need for designers to consider the safety, health and 
well-being of those impacted by the design during construction, maintenance, use and demolition is established in law (HMG, 2015). There is a chain of connections between the decision and actions of the client and designer, through the contractor and workers, to the end user and public who are impacted by a construction project. The legal liability and moral responsibility of all parties are relevant considerations, as within that chain, good, bad and neutral actions result.

Floridi (2016) describes two concepts pertinent to this discourse. Distributed moral actions, which are a class actions whose outputs are either morally good or morally loaded (bad) that are caused by local interactions that are themselves morally neutral (neither good nor bad). This can be applied to events on construction sites; a hospital is a morally good output from many morally neutral interactions, and the building of that hospital is the moral good action. Alternately, an accident follows from morally loaded actions although the individual actions immediately preceding the accident are themselves morally neutral, as many an accident investigator will testify.

The second concept, distributed moral responsibility (DMR), emerges from the end point of a linear matrix of inputs and interactions back to the originating responsibilities that are necessary for the subsequent interactions to occur (Floridi, 2016). DMR falls to those classes of agent at the originating end of the matrix whose input is necessary for all other interactions and ultimate outputs (actions) to occur. The test for an originating responsibility is whether the moral output could occur if that moral agent or class of moral agent was removed from the matrix of local interactions.

The good intentions of the AI designer are immaterial if any resultant morally loaded action is contingent on the system being created in the first instance. Consider, for example, the productivity record of the industry. It lags and has for decades lagged behind other sectors (Barbosa et al., 2017). Worker productivity is regarded by Barbosa et al. (2017) as central to remediating this lag provided that it sets and meets three objectives

a provide higher value to customers with the same or fewer resources

- provide higher-quality structures at a lower cost for owners

- obtain higher profitability for contractors, thus providing higher wages for workers.

Blanco et al. (2018) and UK Construction Online (2019) recognise the under-digitised state of the industry and suggest that AI developments in other sectors may be successfully applied to engineering and construction. However, Barbosa et al. (2017) in advocating these developments and Skillett and Copping (2017) in developing and testing AI productivity systems all recognise the potential for the systems to enhance productivity and be used to negate any worker benefits. Skillett and Copping (2017) refer to the need for further discussion on the ethical application of the technology. However, such a reference admits to but fails to recognise the moral role of developers of AI technology in providing the means for morally loaded exploitation of workers.

The IEEE in their Global Initiative on Ethics of Autonomous and Intelligent Systems (IEEE GIEAIS, 2019) has recognised the potential for beneficent intent to result in morally loaded outputs, once out of the hands of the designers (Winfield et al., 2019), and in their guide to ethically aligned design establishes a set of general principles for the design and development of A/IS, one of which is that creators 'shall guard against all potential misuses and risks of A/IS operation' (IEEE GIEAIS, 2019: p. 4).

The IEEE guidelines are 'offered for consideration by governments, businesses and the public at large in the advancement of technology for the benefit of humans' (IEEE GIEAIS, 2019: p. 5) and encompass other issues, including human rights, well-being, data agency, effectiveness, transparency, accountability and competence (IEEE GIEAIS, 2019: p. 6). In adopting these principles, Sekiguchi and Hori (2020) are developing a practical toolkit for engineers that will facilitate their consideration of ethics issues through the development of a knowledge base that deals with the complex relationships among different $\mathrm{AI}$ ethics and that dynamically adopts new issues to assist engineers in thinking within the context of their own designs.

Utilising a model of design knowledge hierarchies to illustrate relationships between, for example, engineering systems, design units and subunits (Table 2) (Myung and Han (2001), cited by Sekiguchi and Hori (2020)), Sekiguchi and Hori (2020) have inserted two prior levels for consideration by designers: an interaction level and an ethics level (Table 3). The interaction level guides the designer to consider how the artefact creates time, flow and change, while the ethics level considers the social relationships and social values within which the artefact impacts society, the world and the natural environment.

Termed 'design from ethics' level (termed by the developers DfromE), the approach, with or without the tool itself, has some correspondence with the concepts of prevention through design, safety in design and the fundamentals of the Construction (Design

Table 2. Knowledge levels (from Sekiguchi et al. (2009), cited by Sekiguchi and Hori (2020))

\begin{tabular}{ll}
$\begin{array}{l}\text { Knowledge level in a } \\
\text { design hierarchy } \\
\text { (functional) }\end{array}$ & \multicolumn{1}{c}{ Notes } \\
System (user interface) level & $\begin{array}{c}\text { Concerning the interface between } \\
\text { the construction artefact and the } \\
\text { outer environment } \\
\text { Lower-level design considerations }\end{array}$ \\
$\begin{array}{l}\text { Subsystem level } \\
\text { Sub-subsystem level }\end{array}$ & $\begin{array}{l}\text { Lower-level design considerations } \\
\text { Part level }\end{array}$ \\
Material level & Lower-level design considerations \\
\end{tabular}


Table 3. Knowledge levels with additional ethics levels (Sekiguchi and Hori, 2020)

\begin{tabular}{l}
$\begin{array}{l}\text { Knowledge level in a design } \\
\text { hierarchy (with societal and } \\
\text { ethical considerations) }\end{array}$ \\
\hline Ethics level \\
Interaction level
\end{tabular}

and Management) Regulations 2015 in Great Britain and in Northern Ireland (HMG, 2015) - namely, that all are concerned with the ethical issue of worker safety. In these approaches to construction safety, health and well-being are among the first considerations between the designer and the client and the safety objectives established at this point result in the allocation of sufficient resources and the development of practices that ensure safety through the design and construction stages and inform safety in the use, maintenance and demolition of the artefact.

It is thus reasonable to assume that with integrity, the adoption and implementation of ethical principles at the design stage of construction projects, including in construction-related AI systems, will lead to the morally positive (or at minimum morally neutral) outputs.

\section{Conclusions}

In the fourth industrial revolution, AI in many different forms is central to multiple spheres of individual and societal engagement with the world. The technology, both soft and hard, is developing at incredible rates, often being obsolete before it fully impacts the market for it. From a practical viewpoint, it is difficult at times to keep pace with the developments. Technologies that were previously integrated no longer communicate, and their fitness for purpose becomes questionable.

These are practical problems, and solving practical problems is the bread and butter of engineering excellence. However, it is in the sphere of abstract moral and ethical considerations that society experiences discomfort. As AI systems develop the capacity to record, analyse and construct new 'visions' for individual and societal organisation, industries, commerce and governments embrace the potential while voices from within civic society baulk at the potential and decry the actual loss of individual agency.
Nightmarish dystopias abound in fiction and are not infrequently voiced by more rational commentators, yet the moral and philosophical consequences are being considered, debated on and actioned by many rational minds globally at professional, academic and governmental levels (AI HLEG, 2019; FLI, 2019; Floridi, 2016). The pace of technological development may currently be outstripping the development of ethical solutions, but an awareness of the potential for a world of faceless others and respect for the capacity of human intelligence to recognise the issues and seek solutions to critical moral issues are the continual driver of progress in the human ontological project.

As a relative latecomer to the table, construction and engineering are well positioned to learn from the experiences of other sectors as they seek to adopt and adapt the technologies already in use. Construction (and agriculture) is the most transformative of human activities on the planet, impacting every single person, the land and the environment. With a potential for a productivity increase of $50-60 \%$ in the next few years that will add annually US\$1.6 trillion to the global economy (Barbosa et al., 2017), the incentive for the industry to adopt the technologies emerging from AI research and development is enormous.

The challenges to achieving this successfully are, however, equally great: informality in the system, sometimes outright corruption, fragmented structures, mismatched risk allocation, inefficient design, limited standardisation, insufficient planning time and tardy implementation of up-to-date thinking on management and execution. On top of this are bottom-quartile profit margins that constrain investment in the technology (Barbosa et al., 2017).

Effective digitalisation of the industry in the context of meeting societal, industry and worker needs and thus the growth potential outlines requires that the design and development of sector $\mathrm{AI}$ occur within that context and not simply as a technical problem to be resolved by functional algorithms. Design guidelines built on social and ethical principles can achieve this.

As stated by IEEE, 'Ethically Aligned Design sets forth scientific analysis and resources, high-level principles, and actionable recommendations. It offers specific guidance for standards, certification, regulation or legislation for design, manufacture, and use of A/IS that provably aligns with and improves holistic societal well-being' (IEEE GIEAIS, 2019: p. 2).

\section{REFERENCES}

AI HLEG (High-level Expert Group on Artificial Intelligence of the European Commission) (2019) Ethics Guidelines for Trustworthy Artificial Intelligence. European Commission, Brussels, Belgium. See https://ec.europa.eu/newsroom/dae/document.cfm?doc_id=60419 (accessed 16/12/2019).

Andolfo $C$ and Sadeghpour F (2015) A probabilistic accident prediction model for construction sites. Procedia Engineering 123: 15-23, https://doi.org/10.1016/j.proeng.2015.10.052.

Ashe L (2019) 2019: The year of unethical AI ethics? 4S New Orleans 2019: Innovations, Interruptions, Regenerations, New Orleans, LA, 
USA. See https://www.researchgate.net/publication/335677263 2019 The_Year_of_Unethical_AI_Ethics (accessed 19/05/2020).

Baker H, Hallowell MR and Tixier AJP (2019) AI-based prediction of independent construction safety outcomes from universal attributes. ArXiv, 16 August. See https://arxiv.org/abs/1908.05972 (accessed 10/06/2020).

Barbosa F, Woetzel J, Mischke J et al. (2017) Reinventing Construction: a Route to Higher Productivity. McKinsey Global Institute, New York, NY, USA. See https://www.mckinsey.com/\%7E/media/McKinsey/ Industries/Capital\%20Projects\%20and\%20Infrastructure/Our\% 20Insights/Reinventing $\% 20$ construction $\% 20$ through $\% 20 \mathrm{a} \%$ 20 productivity $\% 20$ revolution/MGI-Reinventing-ConstructionExecutive-summary.ashx (accessed 23/03/2020).

Blanco JL, Fuchs S, Parsons M and Ribeirinho MJ (2018) Artificial Intelligence: Construction Technology's Next Frontier. McKinsey Global Institute, New York, NY, USA. See https://www.mckinsey.com/industries/ capital-projects-and-infrastructure/our-insights/artificial-intelligenceconstruction-technologys-next-frontier (accessed 23/03/2020).

BSI (2016) BS 8611:2016: Robots and robotic devices. Guide to the ethical design and application of robots and robotic systems. BSI, London, UK.

Cayley D (2015) Christ and Anti-Christ in the thought of Ivan Illich. davidcayley.com, 22 October. See http://www.davidcayley.com/blog/ 2015/10/22/christ-and-anti-christ-in-the-thought-of-ivan-illich (accessed 18/12/2019).

Choi B, Hwang S and Lee S (2017) What drives construction workers' acceptance of wearable technologies in the workplace? Indoor localization and wearable health devices for occupational safety and health. Automation in Construction 84: 31-41, https://doi.org/10.1016/ j.autcon.2017.08.005.

du Sautoy M (2019) The Creativity Code: How AI Is Learning to Write, Paint and Think. Fourth Estate, London, UK.

Edwards v. National Coal Board [1949]1 All ER 743.

FLI (Future of Life Institute) (2019) Asilomar Principles. FLI, Cambridge, MA, USA. See https://futureoflife.org/ai-principles/?cn-reloaded=1 (accessed 16/12/2019).

Floridi L (2016) Faultless responsibility: on the nature and allocation of moral responsibility for distributed moral actions. Philosophical Transactions of the Royal Society A: Mathematical, Physical and Engineering Sciences 374: article 20160112, https://doi.org/10.1098/ rsta.2016.0112.

Floridi L, Cowls J, Beltrametti M et al. (2018) AI4People - an ethical framework for a good AI society: opportunities, risks, principles, and recommendations. Minds and Machines 28(4): 689-707, https://doi. org/10.1007/s11023-018-9482-5.

HMG (Her Majesty's Government) (2015) The Construction (Design and Management) Regulations 2015. The Stationery Office, London, UK, Statutory Instrument 2015 No. 51.

Hodson H (2014) The subway run by AI. New Scientist 223(2976): 17.

Hogan-Doran D (2017) Computer says 'no': automation, algorithms and artificial intelligence in government decision-making. Journal of the Judicial Commission of New South Wales 13(3): 345-382.

Hovden J, Albrechtsen E and Herrera IA (2010) Is there a need for new theories, models and approaches to occupational accident prevention? Safety Science 48(8): 950-956, https://doi.org/10.1016/j.ssci.2009.06. 002 .

IEEE GIEAIS (Institute of Electrical and Electronics Engineers Global Initiative on Ethics of Autonomous and Intelligent Systems) (2019) Ethically Aligned Design: a Vision for Prioritizing Human Well-being with Autonomous and Intelligent Systems, 1st edn. IEEE New York, NY, USA. See https://standards.ieee.org/content/ieee-standards/en/ industry-connections/ec/autonomous-systems.html (accessed 06/05/2020).

Johnston J (2019) How automated construction will disrupt our industry. PBC Today, 1 February. See https://www.pbctoday.co.uk/news/ planning-construction-news/automated-construction/51936/ (accessed 23/03/2020).

Karaca Kucuk S (2013) Fantastic and Science Fictional Elements in Ray Bradbury's Stories. Master's thesis, University of Yuzuncu Yil, Van, Turkey. See https://www.academia.edu/38147146/FANTASTIC AND _SCIENCE_FICTIONAL_ELEMENTS_IN_RAY_BRADBURY'S STORIES.pdf (accessed 19/05/2020).

Kortuem G, Alford D, Ball L et al. (2007) Sensor networks or smart artifacts? An exploration of organizational issues of an industrial health and safety monitoring system. In UbiComp 2007: Ubiquitous Computing (Krumm J, Abowd GD, Seneviratne A and Strang T (eds)). Springer, Berlin, Germany, pp. 465-482.

Leyden J (2008) Biometrics plan for London Olympic builders. The Register, 5 March. See https://www.theregister.co.uk/2008/03/05/ olympic_biometric_screening_plan/ (accessed 23/03/2020).

Li H, Lu M, Hsu SC, Gray M and Huang T (2015) Proactive behavior-based safety management for construction safety improvement. Safety Science 75: 107-117, https://doi.org/10.1016/j.ssci.2015.01.013.

McAleenan P, McAleenan C, Ayers G, Behm M and Beachem Z (2019) The ethics deficit in occupational safety and health monitoring technologies. Proceedings of the Institution of Civil Engineers Management, Procurement and Law 172(3): 93-100, https://doi.org/ 10.1680/jmapl.18.00027.

Meyer D (2017) Google's new AlphaGo breakthrough could take algorithms where no humans have gone. Yahoo! Finance, 19 October. See https://finance.yahoo.com/news/google-apos-alphagobreakthrough-could-095332226.html?guccounter=1\&guce_referrer= aHR0cHM6Ly9lbi53aWtpcGVkaWEub3JnLw\&guce_referrer_sig= AQAAAMrfUnks79xAAYk4Y4ys7USUqQHrBu2GtuM8uxW9qYjmfaklMw1slG5FeeR0Y0h0ZXkU0kj0Iu -uUGY6DxCMoughcg7j6 V67RgQEHXSPqEdg ZrZHBeMKkzCduyqMWrwpZsCGK40K V7aBqFIvSz-Q7W3uzgx2zwvFdIQTuxdqD (accessed 23/03/2020).

Myung J and Han S (2001) Knowledge-based parametric design of mechanical products based on configuration design method. Expert Systems with Applications 21(2): 99-107, https://doi.org/10.1016/ S0957-4174(01)00030-6.

Pereira L (2018) Artificial intelligence and ethics. Proceedings of Ciência 2018, Lisbon, Portugal. See https://www.researchgate.net/publication/ 326186312 AI and Ethics (accessed 16/12/2019).

Rolf M, Crook N and Steil J (2018) From social interaction to ethical AI: a developmental roadmap. Proceedings of the 2018 Joint IEEE 8th International Conference on Development and Learning and Epigenetic Robotics (ICDL-EpiRob), Tokyo, Japan, pp. 204-211.

Salge C (2017) Asimov's laws wont stop robots from harming humans, so we've developed a better solution. The Conversation, 10 July. See https://theconversation.com/asimovs-laws-wont-stop-robots-harminghumans-so-weve-developed-a-better-solution-80569 (accessed 10/06/2020).

Sekiguchi K, Tanaka K and Hori K (2009) "Design with discourse" to design from the "ethics level". In Information Modelling and Knowledge Bases XXI, Frontiers in Artificial Intelligence and Applications (Družovec TW, Jaakkola H, Kiyoki Y, Tokuda T and Yoshida N (eds)). IOS Press, Amsterdam, the Netherlands, vol. 206, pp. 307-314.

Sekiguchi K and Hori K (2020) Organic and dynamic tool for use with knowledge base of AI ethics for promoting engineers' practice of ethical AI design. AI \& Society 35(1): 51-71, https://doi.org/10.1007/ s00146-018-0867-z.

Skillett G and Copping C (2017) The application of emerging technologies in the measurement of production and productivity data on construction sites. Proceedings of the Joint CIB W099 and TG59 International Safety, Health, and People in Construction Conference, Cape Town, South Africa, pp. 447-458.

UK Construction Online (2019) The benefits of AI in construction. UK Construction Online, 14 February. See https://www.ukconstructionmedia .co.uk/features/benefits-ai-construction/ (accessed 23/03/2020). 
Waber BN, Olguín DO, Kim T et al. (2007) Organizational Engineering Using Sociometric Badges. MIT Media Lab, Cambridge, MA, USA.

Wang W and Siau K (2018) Ethical and moral issues with AI: a case study on healthcare robots. Proceedings of the 24th Americas Conference on Information Systems (AMCIS 2018), New Orleans, LA, USA, pp. 438-442.

Wilson E (2018) Workforce Fatigue Risk Management Using Wearable Technology. Crossrail Ltd, London, UK. See https://learninglegacy. crossrail.co.uk/documents/workforce-fatigue-risk-management-usingwearable-technolgy/ (accessed 23/03/2020).

Winfield A (2017) A round up of robotics and AI ethics. Alan Winfield's Web Log, 23 December. See https://alanwinfield.blogspot.com/2017/ (accessed 18/05/2020).
Winfield A (2019) Ethical standards in robotics and AI. Nature Electronics 2(2): 46-48, https://doi.org/10.1038/s41928-019-0213-6.

Winfield A, Michael M, Pitt J and Evers V (2019) Machine ethics: the design and governance of ethical $\mathrm{AI}$ and autonomous systems. Proceedings of the IEEE 107(3): 509-517, https://doi.org/10.1109/JPROC.2019.2900622.

Yu Y, Guo H, Ding Q, Li H and Skitmore M (2017) An experimental study of real-time identification of construction workers' unsafe behaviors. Automation in Construction 82: 193-206, https://doi.org/10.1016/j. autcon.2017.05.002.

Zeng Y, Lu E, Sun Y and Tian R (2019) Responsible facial recognition and beyond. ResearchGate, September. See https://www.researchgate.net/ publication/336147376_Responsible_Facial_Recognition_and_Beyond (accessed 19/05/2020)

\section{How can you contribute?}

To discuss this paper, please email up to 500 words to the editor at journals@ice.org.uk. Your contribution will be forwarded to the author(s) for a reply and, if considered appropriate by the editorial board, it will be published as discussion in a future issue of the journal.

Proceedings journals rely entirely on contributions from the civil engineering profession (and allied disciplines). Information about how to submit your paper online is available at www.icevirtuallibrary.com/page/authors, where you will also find detailed author guidelines. 